\title{
Lei, Ética e Alienação do Desejo: Interpretação Psicanalítica e Jurídica dos Laços Sociais no Capitalismo Contemporâneo
}

\section{Dorothee Susanne Rudiger}

Doutora em Direito pela Universidade de São Paulo (1995). Professora no Programa de Mestrado e Doutorado da Universidade Católica de Santos. Membro do corpo de formação do Instituto da Psicanálise Lacaniana. E-mail: dorotheerudiger@gmail.com

Resumo: O artigo reúne reflexões do direito e da psicanálise sobre o desejo e os laços sociais contemporâneos. Estranho ao direito moderno, o desejo é abordado como consequência da lei, que possibilita a convivência civilizada. Em uma perspectiva metodológica de abordagem dialética, o artigo discute a descoberta do inconsciente no contexto histórico do movimento da "destruição criativa" do capitalismo. Além disso, aborda as consequências da alienação do desejo em diversos campos do saber jurídico. Na perspectiva da ética da psicanálise, que diverge da base moral do direito moderno, investiga novas possibilidades de criação e manutenção de laços amorosos e sociais pela garantia jurídica de participação nos espaços locais, regionais e globais - no âmbito social e político. Propõe a partir da psicanálise um debate no campo do direito visando a superação da perspectiva moderna do justo balanço entre os direitos e obrigações. Conclui que o direito, dessa maneira, terá a chance de servir como instrumento de uma transformação criativa da sociedade, na qual os laços afetivos tomarão o lugar central.

Palavras-chave: Direito e psicanálise. Direito e laços sociais. Direito e pósmodernidade.

\section{UNIVERSIDADE FEDERAL DA PARAÍBA}

João Pessoa, Programa de Pós-Graduação em Ciências Jurídicas 


\title{
Lei, Ética e Alienação do Desejo: Interpretação Psicanalítica e Jurídica dos Laços Sociais no Capitalismo Contemporâneo
}

\author{
Dorothee Susanne Rudiger
}

\section{INTRODUÇÃO}

O desejo, esse inominável motor da ação humana, é objeto principal do presente artigo. Escapando dos limites da lei, tomada no sentido mais amplo que a palavra possa ter, o desejo guarda, com esta, uma íntima ligação, pois, sem os limites das normas que regem a convivência numa determinada sociedade, não há desejo. Ocorre que cada sociedade historicamente lida com as normas e, portanto, com o desejo, de uma maneira particular. Assim, o desejo pode ser reprimido, negado, sujeitado e recalcado, tal como na sociedade industrial, que exige a disciplina dos corpos para a produção de lucro. $\mathrm{Ou}$, então, pode ser manipulado e alienando para fins consumistas, como ocorre na sociedade contemporânea. Mas, principalmente, o desejo produz laços sociais que, por sua vez, têm no direito uma das maneiras de sua formatação.

Todavia, o desejo é um terreno estranho para a maioria dos estudiosos do direito. Pretendemos oferecer aqui uma leitura psicanalítica da função da lei e do desejo na criação e manutenção dos laços sociais na sociedade do século XXI, marcados, nem tanto pela disciplina, mas pelo hedonismo do capitalismo pós-moderno. 
Lei, Ética e Alienação do Desejo: Interpretação Psicanalítica...

Tradicionalmente imposta desde a infância pela autoridade paterna, reforçada pela moral social e mantida por sanções, imaginárias ou palpáveis, a lei é responsável pela busca por satisfação do ser humano na civilização. A imposição da lei é, portanto, fundamental para a formatação dos laços sociais. A psicanálise reconhece essa função da lei, isto é, de estabelecer limites às pulsões humanas em nome da convivência em sociedade, mas ocupa uma visão da ética do desejo que consiste em defender o ser humano que sofre das consequências da repressão moral e permitir que o desejo se manifeste na constante reinvenção da civilização humana. Em outras palavras, a posição da psicanálise é a de atuar para possibilitar que o desejo humano desenvolva a criatividade quando se destinar a outro ser humano.

Essa visão psicanalítica da lei foge da visão do direito moderno, que, tendo suas bases na filosofia iluminista e, posteriormente, no positivismo jurídico, guarda uma visão racionalista de um homem idealizado. Ainda na atualidade, para o direito civil e penal, para citarmos dois exemplos, o sujeito de direito é dotado de razão, sabe o que faz, age deixando-se guiar por escolhas racionais, exerce sua liberdade, sua autonomia da vontade. Atitudes imaturas, insensatas e inconscientes são contempladas pelo direito positivo como sendo exceção da regra da sensatez do exercício racional da vontade livre. O desejo, em outras palavras, é tratado como exceção da regra do pensar e do agir racional do homem médio adulto.

A psicanálise, campo do saber criado por Sigmund Freud, trata da lei e do desejo no contexto do processo civilizatório que, na sociedade capitalista, carrega a marca da "destruição criativa". O capitalismo constrói paisagens urbanas, obras que se fazem valer do desenvolvimento da ciência e da tecnologia; produz objetos que, além de sua utilidade, carregam um valor imaginário que promete, ao menos por instantes, aquietar uma busca por algo inominável e satisfazer o desejo. O consumo, a aquisição de objetos, é, nesse contexto, a justa recompensa pela disciplina do corpo e o regramento 
da sexualidade, necessários para o funcionamento da sociedade em geral e do trabalho em especial.

No contexto do capitalismo contemporâneo, há uma mudança fundamental entre lei, civilização, desejo, criação e destruição. Despertado pelos limites que a sociedade impõe a cada um e, ainda, responsável pela destruição e reinvenção incansável da civilização, o desejo é alienado, desviado de sua função criadora de laços amorosos e sociais. O capitalismo, aparentemente, não exige o sacrifício do desejo para recompensas futuras. Seduz com estratégias de publicidade que pretendem direcionar o desejo para os inúmeros objetos oferecidos para o consumo. A alienação do desejo para o consumo imediato e desenfreado dos produtos globalmente oferecidos é capaz de desviar o desejo de sua maior função, que é a de estabelecer e manter laços amorosos e sociais. Dentre outras consequências, a alienação é responsável por um crescente narcisismo, uma retração psíquica para dentro de si mesmo que, no limite, deprime. "Vivemos", de acordo com Domenico de Masi (2017), "numa época triste".

Essa tristeza manifesta-se também como problema no campo do saber jurídico. Podemos citar o direito do trabalho, que, atualmente, lida com a depressão como uma doença que afasta milhões de trabalhadores no mundo do trabalho. As transformações dos laços sociais que observamos na contemporaneidade, oriundos de "amores líquidos" - termo cunhado por Zygmunt Bauman (2004) - afetam as relações familiares. Nossas identidades alteradas, tematizadas pela psicanálise, são um desafio para o direito da família, obrigado a lidar, por exemplo, com as alterações nas identidades sexuais. É tema para o direito penal - desafiado a debater a diferença entre o "normal" e o "patológico" no comportamento humano. A alienação do desejo afeta o direito do consumidor, que trata, dentre outros, do problema do superendividamento e de suas consequências. Diante disso, o objetivo do presente ensaio não é nem tanto dar uma contribuição para a filosofia ou para a teoria geral do 
Lei, Ética e Alienação do Desejo: Interpretação Psicanalítica...

direito, mas instigar as reflexões sobre os laços afetivos e sociais que estão na base do direito.

Tanto o direito quanto a psicanálise fundam-se numa práxis. Experimentam a presença de conflitos humanos, sejam eles conflitos de interesses, que demandam soluções ao direito, ou conflitos entre o ser humano e a civilização, que demandam a intervenção do psicanalista. Daí decorre que a premissa metodológica para uma abordagem psicanalítica das questões levantadas pela modificação dos laços sociais na contemporaneidade é a dialética, proposta na obra de Sigmund Freud ([1930] 2004) como a necessidade humana de viver na civilização e o mal-estar que causa. De acordo com essa visão dialética, somos todos alienados, seja pelo imaginário do Complexo de Édipo, proposto por Freud ao longo de sua obra como chave de leitura do inconsciente, seja pela linguagem com a qual a civilização "banha" o ser humano para torná-lo sujeito, como quer Jacques Lacan em seus escritos e seminários. É importante dizer que, na visão dialética da psicanálise, não há síntese, não há conciliação possível no conflito entre o sujeito e a civilização. Há um resto, uma zona de desconforto entre o homem e o mundo, simbólico ou imaginário.

Como veremos, há, para alguns juristas contemporâneos, uma zona de "anomia" também no direito, pontos cegos da lei, incapazes de abranger a vida em sua totalidade. A zona que Lacan ao longo de sua obra chama de "o Real" é a zona do desejo. Devastador ou criativo, transforma o cenário da civilização rompendo e estabelecendo laços afetivos e sociais. Está, com isso, próximo ao direito que os delimita e promove. Esse ato criativo, no entanto, só é possível quando se privilegia a ética do desejo. 


\section{2 ÉTICA OU ALIENAÇÃO DO DESEJO?}

O menino é travesso. Tenta subir uma escada, pendura-se na prateleira do armário, mete a tesoura no cabelo da boneca da irmã e joga futebol na sala, enquanto uma trilha sonora repete a palavra "não” ao som de uma composição de Wolfgang Amadeus Mozart. "A mãe tem que falar não", diz o spot de reclame, para proteger a criança, em primeiro lugar, de si mesma. Mas o menino merece também um “sim”. Quando obedece, a mãe lhe oferece um bastão de chocolate.

A publicidade de uma grande marca de chocolate (W/MacCANN, 2014) trata, de maneira criativa, mas ao mesmo tempo polêmica, da lei, do desejo e dos objetos que a sociedade capitalista é capaz de oferecer para, aparentemente, satisfazer os desejos dos que se sujeitam a seus comandos. É um exemplo de como a lei e o desejo são tratados pelo capitalismo. Reconhecendo a existência de um desejo, posto em movimento pela imposição de limites, oferece seus produtos como justa compensação pelo malestar que a imposição da lei do "não-faça” possa causar.

Por que se deveria estudar, no campo do saber jurídico, a alienação e a ética do desejo, tal como propõe a psicanálise? A psicanálise é um campo do saber cujo objeto de estudo, o inconsciente, segue uma lógica paradoxal. Permite o abrigo de contradições, tais como o amor e o ódio pela mesma pessoa, e explica a presença de pulsões de vida e de morte. A psicanálise dá instrumentos para a interpretação de um mundo percebido como estranho e assustador: a sexualidade humana. É uma práxis de escuta daquilo que o ser humano tem de irracional e que lhe causa sofrimento. Mais que sua teoria, importa para a psicanálise a atitude 
Lei, Ética e Alienação do Desejo: Interpretação Psicanalítica...

do psicanalista diante do sofrimento humano e a conduta do paciente diante da impossibilidade de escapar dos ditames da civilização. Herdeira da medicina, convida à fala sem censura e à escuta sem preconceito. Por isso, a psicanálise advoga a ética e não a alienação do desejo (LACAN, [1958] 1998).

Por outro lado, escutando o sofrimento do ser humano, a psicanálise, tal como o direito, investiga os laços sociais e suas formas de regulação. Faz isso a partir de uma visão da subjetividade marcada pela irracionalidade. Contrapõe-se, assim, a concepções modernas do direito, que tomam a racionalidade e a consciência livre como bases do direito. Atualmente, tanto o direito quanto a psicanálise estudam as mudanças nos laços sociais e, consequentemente, na regulação social na pós-modernidade.

Para a análise dos novos laços sociais, é particularmente importante a contribuição da obra do psicanalista francês Jacques Lacan. Nos anos 1960, Lacan percebia em sua clínica que novas maneiras de regulação social estavam se formando, e que estas, paulatinamente, dispensavam as grandes figuras paternas (o pai, o chefe de Estado, o empresário) como representantes da lei. Davam lugar a novos laços sociais horizontais, que, mais tarde, com os avanços tecnológicos da informática, seriam organizados pelo que se chama "a sociedade em rede".

Partimos do pressuposto que o direito é estruturante para os laços sociais, uma vez que é um "sistema de comunicação formulado em termos de normas para permitir a realização de um sistema determinado de produção e de trocas econômicas e sociais" (MIAILLE, 2005, p. 96). Esse sistema não é estático, mas dinâmico, é um ordenamento, não uma ordem, composto por várias fontes sociais, que variam de acordo com o local e o tempo, e pela correlação de forças da sociedade civil, na qual "vigem normas de vários gêneros, morais, sociais, religiosas, usuais, consuetudinárias, regras convencionais e assim por diante" (BOBBIO, 1997, p. 41-42).

Cabe, portanto, investigar, por meio dos instrumentos conceituais da psicanálise, em que medida as formas de regulação 
social contemporâneas, incluindo o direito, constituem, não apenas objetivamente, como também subjetivamente, a convivência em sociedade. O que se propõe no presente estudo é discutir, no contexto da relação dialética entre a civilização e a subjetividade, os desafios e as possibilidades do direito contemporâneo quando se trata da reinvenção do exercício de direitos fundamentais. Em nosso empreendimento, passamos pela teoria psicanalítica de Sigmund Freud, desenvolvida na sociedade industrial, caraterizada pela disciplina do corpo, a redução do trabalho vivo a uma mercadoria, e o desejo travado pela moral e pela "lei do pai" (FORBES, 2012). Chegamos às discussões da psicanálise contemporânea que, tal como o direito, hoje, é obrigada a lidar com as consequências psíquicas das mudanças na regulação social na pós-modernidade, na qual não se oprime o desejo, mas o desperta e aliena para seus fins.

\section{A PSICANÁlise e A ÉTICA do DESEJO}

Sigmund Freud atribui a descoberta do inconsciente ao médico neurologista Joseph Breuer e à sua paciente chamada Anna O. (BREUER; FREUD, [1895] 2007), uma moça de 21 anos de idade que se queixa para Breuer de dores no braço. No entanto, mais do que as dores no braço, chama atenção seu comportamento estranho: comunicando-se somente em inglês, não consegue tomar água e apresenta estranhos devaneios. Joseph Breuer, sensível ao pedido da paciente para deixá-la falar, escuta essa moça que, embora 
Lei, Ética e Alienação do Desejo: Interpretação Psicanalítica...

inteligente, encontra-se desocupada, condenada a um casamento por conveniência e sexualmente reprimida, como muitas moças de sua classe social à época. Cenas traumáticas ligadas à doença e à morte do pai e ao nojo que sente do cão da governanta inglesa revelam a Joseph Breuer a existência de uma double conscience (BREUER; FREUD, [1895] 2007). O que, mais tarde, Sigmund Freud chamará de inconsciente não aparece somente nos devaneios de pacientes como Anna O. Se faz perceber também nas cenas do cotidiano: nos chistes, nos atos falhos, nos sintomas de doenças sem causa física aparente e, principalmente, nos sonhos.

Naquilo que Sigmund Freud chama de "a outra cena", no inconsciente, atua um desejo sempre insatisfeito. Freud dá, em sua obra $A$ interpretação dos sonhos, um exemplo dessa insatisfação como causa do desejo e, portanto, motor de uma procura incessante por algo que não tem correspondente no mundo. Uma jovem senhora, esposa de um açougueiro, sonha oferecer um jantar. No entanto, possui em sua dispensa apenas um resto de salmão. É domingo. As lojas estão fechadas e seu telefone não funciona. Assim, ela está impedida de promover o jantar. Interpretando o sonho, Sigmund Freud revela à paciente algo surpreendente: a paciente não quer ter seu desejo satisfeito, quer mantê-lo aberto. O desejo, conclui Sigmund Freud, é vivo, enquanto está impossibilitado de ser realizado, está insatisfeito. Se satisfeito, o desejo morre (FREUD, [1900] 2007).

A dialética entre a lei e o desejo é abordada por Sigmund Freud em sua obra $O$ mal-estar na civilização. No original da obra, em alemão, chamada Das Unbehagen in der Kultur (O mal-estar na cultura), o autor contrapõe a cultura à natureza humana, defendendo como tese central que a cultura marca o ser humano, revestindo-o como se fosse um segundo corpo (FREUD, [1930] 2004). Seres dependentes da cultura construída a partir da fala, somos, desde que nascemos, protegidos e, ao mesmo tempo, incomodados pela cultura, ou, como preferem os tradutores das obras de Sigmund Freud, pela civilização. Desde cedo, apreendemos que, para o ser humano, a vida 
civilizada tem um preço: a verdadeira perda do paraíso da vida natural. Somos separados da mãe e sujeitos à lei da proibição do incesto. Em nome da convivência em sociedade, devemos obediência a essa norma que Hans Kelsen, interlocutor de Sigmund Freud (FORBES, 2012), chama de Grundnorm - mãe de todas as normas. Podemos procurar no amor romântico, na religião, na loucura, nas drogas, na arte as mais variadas formas de fugir do mal-estar que a civilização e a lei nos causam. No entanto, para Sigmund Freud, não há escapatória: se quisermos conviver em sociedade, a obediência à lei é tão vital a ponto de criarmos em nosso aparato psíquico uma instância, o superego, que nos previne da desobediência à lei. Por outro lado, nasce, a partir da imposição da lei, da castração simbólica, o desejo de voltar a encontrar o que nos foi tomado pela necessidade de conviver em sociedade, ou seja, a plenitude da vida em harmonia com a natureza. Paradoxalmente, o desejo só tem um lugar onde possa se realizar: na civilização.

Os caminhos do desejo são tortuosos. Sigmund Freud, no início do desenvolvimento da teoria psicanalítica, acreditava que o desejo estava destinado a buscar prazer na sexualidade, mas é forçado a modificar sua teoria depois da Primeira Guerra Mundial. A morte em massa causada pela guerra e, principalmente, os efeitos dos traumas sofridos pelos soldados nos seus sonhos, fazem com que Freud desenvolva uma teoria das pulsões, que dá conta da presença de um estranho prazer humano: o de construir e, ao mesmo tempo, destruir. Eros e Tânatos, pulsão de vida e pulsão de morte, são duas respostas humanas para o inevitável: a castração e o sofrimento causado por ela (FREUD, [1920] 2007). Chama atenção o paralelo entre a descoberta de Freud sobre a existência de duas pulsões contraditórias, que se manifestam no inconsciente, e o movimento revolucionário do capitalismo, descrito por Karl Marx e Friedrich Engels no Manifesto Comunista, que consiste na permanente criação e destruição:

Essa subversão contínua da produção, esse abalo constante de todo o sistema social, essa agitação permanente e essa falta de segurança distinguem a época 
Lei, Ética e Alienação do Desejo: Interpretação Psicanalítica...

burguesa de todas as precedentes. Dissolvem-se todas as relações sociais antigas e cristalizadas, com seu cortejo de ideias secularmente veneradas; as relações que as substituem tornam-se antiquadas antes mesmo de ossificar-se. Tudo que era sólido e estável se esfuma, tudo que era sagrado é profanado (...) (MARX; ENGELS, [1848] 1980, p. 12).

O tema da existência de duas pulsões paradoxais e da consequente destruição criativa como movimento inconsciente é retomado e aprofundado pelo psicanalista francês Jacques Lacan.

\section{DESTRUIÇÃO E CRIAÇÃO: O PARADOXO DO GOZO}

Jacques Lacan, psicanalista francês ligado, no início do século $\mathrm{XX}$, ao estruturalismo e ao existencialismo - movimentos que reuniam artistas e intelectuais como Pablo Picasso, Salvador Dalí, Jean Paul Sartre, Simone de Beauvoir e Claude Lévi-Strauss -, reinterpreta a teoria das pulsões de Freud, enfatizando o papel atribuído à civilização na formação da estrutura psíquica do sujeito e do movimento criador e destruidor do desejo à procura de um objeto. Sendo sujeitos à civilização humana e a suas leis, procuramos algo que Lacan chama de "objeto a". O "objeto a" é um objeto de satisfação que se perdeu na primeira infância, quando a criança é obrigada a se separar paulatinamente da mãe, e tem os seus primeiros contatos com a civilização. Esse objeto é a causa do desejo. Esperamos encontrar algo que satisfaça para sempre o desejo na própria civilização, no que Lacan chama, referindo-se a Hegel, de o "Outro", o "tesouro dos significantes". Mas não há na civilização esse "algo". Pelo contrário, há uma constante procura e frustração. Habitamos uma "máquina de significações" e de destruição que, incessantemente, manda recomeçar a procura: "Vontade de 
destruição. Vontade de recomeçar com novos custos. Vontade de Outra-coisa, na medida em que tudo pode ser posto em causa a partir da função do significante." (LACAN, [1959-1960] 2008, p. 254).

Esse movimento paradoxal, o qual Lacan chama de "gozo", não existe para satisfazer necessidades. Vai além. Busca algo inominável e, por isso, destrói e, ao mesmo tempo, inventa o novo. O movimento do desejo é histórico, ou, nas palavras de Walter Benjamin, "o futuro constrói-se sobre os destroços do passado." (BENJAMIN, [1940] 2012, p.14). Para o economista Joseph Schumpeter ([1943] 2003, p. 83), a destruição criativa é a dinâmica que atua dentro da estrutura do sistema econômico vigente, "incessantemente destruindo a antiga, incessantemente criando uma nova. Esse processo de Destruição Criativa é o fato essencial sobre o capitalismo. É no que o capitalismo consiste e o que todo conglomerado capitalista deve experimentar."

Como já foi dito, para a psicanálise de orientação lacaniana, o movimento incessante de destruição e renovação, presente na sociedade moderna em geral, deve-se à perda, na primeira infância, de um "objeto causa do desejo" sacrificado em nome da preparação da criança para a convivência em sociedade (LACAN, [1964] 2008). Esse objeto pode ser um dos chamados "objetos parciais", descritos por Sigmund Freud ([1915] 2007) como para sempre perdidos: peito, olhar, voz da mãe ou então as fezes, sacrificadas em nome da higiene humana. Essa procura pelo objeto perdido é inconsciente. Por outro lado, a civilização não é capaz de fornecer ao ser humano aquilo que é objeto de sua procura incessante pelo estado de completude perdido em decorrência de sua convivência em sociedade.

Essa cisão entre aquilo que desejamos e aquilo que a civilização moderna pode nos oferecer, dificilmente é perceptível nas construções simbólicas que regem a sociedade. Há várias maneiras de se negar a presença desse gap e do objeto causa do desejo que produz. Assim, na sociedade moderna e, principalmente, no direito

1 "(...) incessantly destroying the old one, incessantly creating a new one. This process of Creative Destruction is the essential fact about capitalism. It is what capitalism consists in and what every capitalist concern has got to live in." 
Lei, Ética e Alienação do Desejo: Interpretação Psicanalítica...

moderno, construído no pressuposto da racionalidade do sujeito (BITTAR; ALMEIDA, 2010), não há espaço para as incongruências que, para os psicanalistas, se apresentam no inconsciente. Obedecemos às regras do conhecimento, produzimos teses e provas e seguimos a normas jurídicas que, no direito moderno, baseiam-se na ideia do contrato, da troca, do toma lá dá cá e do exercício da autonomia da vontade. A conquista de direitos econômicos, culturais e sociais, individuais, coletivos e difusos, não modifica essa concepção do direito. Procura, por meio de normas protetoras, proporcionar aos hipossuficientes o exercício racional da autonomia da vontade e, pela garantia do exercício da negociação coletiva, restaurar sua capacidade de se dar normas, sua autonomia privada (RÜDIGER, 1999, p. 79 s).

No entanto, as equações nas trocas existentes na civilização, formalizadas pelo direito - um dentre outros sistemas simbólicos não resistem à realidade da sexualidade humana e do inconsciente impulsionado pelo desejo (LACAN, [1964] 2008, p. 149). "O direito", diz Jacques Lacan ([1972-1973] 1975, p. 10), "estreita o gozo". Encontra formas de adequar e regulamentar o exercício da sexualidade. "Lacan toma o exemplo do uso do concubinato (deitar junto) que se funda no direito. Ele lembra que no direito fica velado o que ali, no leito se faz." (FORBES, 2012, p. 38). Função do direito é criar um mundo justificado que ordena o gozo sem considerar seus excessos: "repartir, distribuir, retribuir, o que diz respeito ao gozo." (LACAN, [1972-1973] 1975，p. 11). No direito, enfim, há uma justaposição entre limitações, obrigações e direitos que não deixam margem para a ideia da existência de um excedente.

Esse mundo jurídico "perfeito" é apenas uma representação simbólica de uma realidade que inclui o contingente, o inarrável, a morte, ou aquilo que Jacques Lacan, ao longo de sua obra, chama de "o Real". Assim como não há harmonia possível entre um casal, porque há um jeito masculino e outro feminino de viver a sexualidade, as equações, tais como praticadas no campo do direito, são construções discursivas, ou seja, aquilo que Karl Marx chama de 
ideologia. São "linguagem da vida real" (MARX, [1845] 1980, p. 25). Tanto quanto a mais-valia, o objeto causa do desejo - que Jacques Lacan chama de "objeto mais-de-gozar" - é aquilo que não encontra um lugar adequado no mundo, mas constitui o motor da civilização (LACAN, [1969-1970] 1991, p.167). Para a psicanálise, não há na civilização objeto que possa restituir ao ser humano a plenitude da vida natural. Diante dos sacrifícios que a convivência em sociedade exige, há as possibilidades de invenção criativa ou, como quer Sigmund Freud, de "sublimação" na ciência, na arte e no desenvolvimento geral de ideias (FREUD, [1930] 2004, p. 53).

\section{DESEJO, LEI E ALIENAÇÃO NA PÓS-MODERNIDADE}

A psicanálise, como campo do saber, foi desenvolvida por Sigmund Freud e seus discípulos no contexto da modernidade e da ciência como sistema universal de explicação do mundo. Assim sendo, o sujeito do inconsciente é o outro lado de uma mesma medalha, mediante a qual o direito natural e os direitos humanos apontam o ser humano como sujeito universal. Esse sujeito é, de acordo com Jacques Lacan, um "sujeito sem qualidades" que se deixa reduzir a uma mercadoria, um objeto de compra e venda:

Para Lacan, existe uma analogia entre o sujeito do inconsciente e o trabalhador, na modernidade capitalista. É o sujeito que renuncia ao usufruto imediato do seu corpo e de seu desejo para recuperá-lo sob a forma de gozo-a-mais, um mais-de-gozar. [...]o trabalho deixa de servir para produção do necessário, mas serve para produzir excedente[...] O homem modifica também sua relação com o prazer. Dedica menos tempo ao ócio e o 
tempo de lazer converte-se, pouco a pouco, no tempo dedicado ao consumo da mercadoria excedente. (FORBES, 2012, p.VII)

A pós-modernidade radicaliza a "destruição criativa" que marca a modernidade. Acentua seu lado fragmentário, efêmero, descontínuo e caótico (HARVEY, 1998, p. 49), e, podemos acrescentar, consumista. Ocorre num cenário econômico e político global, no qual, objetivamente e subjetivamente, os laços sociais e suas representações, até então existentes, são postos em xeque. Assim, em decorrência do movimento estudantil de maio de 1968, os grandes paradigmas nos campos do saber e da sensibilidade, tais como: a verdade na ciência, a emancipação na política, o belo na arte, e a justiça no direito, são abordados, para usarmos um termo de Jean-François Lyotard (1998, p. 35), como "grandes narrativas", ou seja, resultados de convenções entre experts, meros jogos de linguagem.

Marcadas pela verticalidade, algumas instituições que tinham na relação entre pai e filhos seu grande modelo, entram em crise, entre elas: a família patriarcal, o Estado-providência e a empresa organizada nos moldes da administração fordista.

A sociedade vitoriana que inspirou Freud no sentido de formular a hipótese da universalidade do Complexo de Édipo conservava, graças à persistência dos resíduos da ordem patriarcal, a função do pai no âmbito de suporte das identificações ao ideal. Hoje, seria preciso repensar a questão da universalidade do ideal. Dada a fragmentação das representações de mundo, dos ideais e da multiplicação das modalidades de laço social, não é mais possível apreender a função do pai pelo viés da transmissão do laço a algum universal. (FORBES, 2012, p. 45).

Diante disso, a teoria do Complexo de Édipo, criada por Sigmund Freud para descrever a mescla entre amor, ódio e culpa que a criança sente em relação a seus pais, em decorrência da proibição do incesto, e tida, até os anos 1960, como a chave de interpretação do inconsciente, não resiste à desconstrução da sociedade patriarcal. Para Jacques Lacan ([1969-1970] 1991), o Complexo de Édipo é uma 
tentativa de compreensão do inconsciente a partir de um sonho de Sigmund Freud que revela um fato inexorável: pela necessidade de convivência com a civilização humana, todos são castrados, inclusive o pai. Não são mais as grandes figuras paternas que norteiam os laços sociais. Consequentemente, falta a necessidade da obediência à lei como elemento estruturante da civilização e de um sujeito que, na sociedade edípica, tinha que postergar a realização de seu desejo. Abre-se agora espaço para a "enxurrada de coisas" que a civilização capitalista superconsumista lança permanentemente como objetos do desejo, chamadas por Lacan de Latusas. Estas encontram-se "na saída para a calçada, em todas as esquinas da rua, atrás de todas as vitrines, que são objetos feitos para causar seu desejo, pois agora é a ciência quem governa." (LACAN, [1969-1970] 1991, p. 174)

Por outro lado, diante da ausência de um norte que, antes, era dado pelas grandes figuras paternas, diante do imediatismo, do efêmero perceptível no dia a dia da sociedade global, o direito, como sistema de organização social, está construído em torno de um vácuo, de uma zona de "anomia" cada vez maior. Para Giorgio Agamben (2004, p. 48), com a globalização tornou-se evidente essa lacuna existente entre a lei e a realidade: "A lacuna não é interna à lei, mas diz respeito a sua relação com a realidade, a possibilidade mesma de sua aplicação.” Não há, em outras palavras, correspondência entre a realidade social e suas normas. Consequentemente, não há soluções, a priori, que o direito possa oferecer para a normatização de uma sociedade em constante movimento. Há, sim, possibilidades de regulação social a partir daquilo que Jean-François Lyotard (1998, p. 119) chama de "pequenas narrativas", a negociação constante de soluções ad hoc: "Esta orientação corresponde à evolução de interações sociais, onde o contrato temporário suplanta de fato a instituição permanente de matérias profissionais, afetivas, sexuais, culturais, familiares e internacionais, como nos negócios políticos.”. Em outras palavras, a negociação permanente e o contrato em todas suas dimensões dominam o cenário jurídico. 
Lei, Ética e Alienação do Desejo: Interpretação Psicanalítica...

Como em qualquer civilização, há lei também na pósmodernidade. Sendo seres humanos, continuamos sofrendo dos limites que a convivência na civilização nos impõe. Mas, se não pela lei do pai, no que somos "castrados", barrados, limitados? Para Jacques Lacan ([1972-1973] 1975), a própria civilização é limitada quando não consegue oferecer ao ser humano uma linguagem que possa expressar seus afetos, principalmente no que se trata da sexualidade. Somos, portanto, castrados pela linguagem. Não há correspondência entre aquilo que conseguimos expressar pela linguagem e aquilo que sentimos; não há, por isso, entendimento perfeito entre duas pessoas. Há uma falha entre as palavras e os afetos. No decorrer da vida, perdemos a capacidade contida no que Lacan ([1972-1973]1975) chama de lalangue (lalingua), uma língua carregada de afetos com a qual crianças pequenas se expressam. A lalangue constitui uma verdadeira memória afetiva no inconsciente, enquanto o gap entre os afetos e sua possibilidade de expressão pela linguagem, chamado por Lacan de "o Real", passa a dominar essa "outra cena".

A defasagem entre a identidade do sujeito e as possibilidades de sua representação constata-se, para Lacan ([1949] 1998), também no registro do Imaginário. Se, por um lado, um bebê de sete meses se reconhece no espelho e constrói, a partir da imagem refletida (ou então no rosto de outra criança ou até de um adulto), o "Eu", por outro lado, percebe, ao mesmo tempo, um estranhamento. A imagem pode ser somente uma representação, não sendo idêntica com o "Eu". Tal como na dificuldade de expressar afetos por palavras, vai ter dificuldade de se identificar com sua imagem, porque há um gap, algo que a imagem não representa.

Na civilização, não há linguagem que dê nome para tudo. A linguagem é capaz apenas de tangenciar o real, isto é, o desconhecido, o inesperado, a morte e a sexualidade. Isso causa angústia: "A angústia é esse corte - esse corte nítido, sem o qual a presença do significante, seu funcionamento, seu sulco no real é impensável...”, diz Jacques Lacan ([1962-1963] 2005, p. 88). 
Na sociedade global, essa angústia só aumenta, já que o real se expande. Na medida em que aumenta a angústia, cresce o consumo de objetos, inclusive, de drogas lícitas e ilícitas. Proliferam distúrbios alimentares (magreza e obesidade) e, para dar vazão à falta de palavras que seriam necessárias para se dar conta de viver na complexa sociedade global, os casos de "violência inusitada", sem causa aparente, multiplicam-se (FORBES, 2012). Ademais, o esgarçamento dos laços sociais, construídos ao longo da sociedade industrial, está causando uma verdadeira pandemia de depressão no mundo do trabalho contemporâneo.

Por um lado, isso é devido à introdução de formas flexíveis de administração do trabalho; por outro, à dificuldade generalizada de estabelecer novos laços afetivos (RÜDIGER, 2014). Se hoje os meios de comunicação contemporâneos possibilitam jornadas flexíveis de trabalho e uma administração mais individualizada do tempo, proporcionam também a disponibilidade do trabalhador em tempo real, ou seja, o following the sun. Se para esse trabalhador não há outra compensação para o trabalho a não ser a pecuniária, que possibilita o consumo e a alienação do desejo em seus objetos, a depressão pode se instalar. No limite, a pessoa não mais procurará estabelecer e manter laços afetivos com outras pessoas, mas desejará adquirir, com o fruto de seu sobretrabalho, objetos mortos, isto é, mercadorias intercambiáveis e "sem alma" (RÜDIGER, 2016, p. 51).

Tanto a culpa inculcada pela moral quanto o empuxe para o consumo desenfreado alienam o desejo. O que pode a psicanálise - a "cura pela palavra" ou talking cure, inventada no século XIX - contra o sofrimento dos homens e das mulheres do século XXI, no qual padecem nem tanto pela repressão do desejo, mas pela sua alienação? O que oferece para os que recorrem à violência, às drogas, e aos que estão em depressão? A psicanálise questiona a moral dominante numa sociedade. Se essa moral manda gozar a qualquer preço, manda alienar o desejo nos objetos oferecidos pelo mercado, a psicanálise possibilita a cada um, singularmente, aguentar a angústia que a civilização proporciona para dela fazer um motor da 
Lei, Ética e Alienação do Desejo: Interpretação Psicanalítica...

criatividade, da arte - no sentido mais amplo da palavra-, e assumir a responsabilidade pela criação (FORBES, 2012). É esse o caminho da ética singular, da atitude a se tomar no divã da psicanálise diante dos desafios que a civilização não cessa em colocar diante de cada um. No entanto, questiona-se como a psicanálise pode contribuir com o debate e a práxis do direito, tradicionalmente marcado pela sua universalidade e não pela singularidade?

Essa contribuição urge, uma vez que "se evidencia globalmente a defasagem endêmica entre a garantia dos direitos sociais, contida nos documentos internacionais e nas constituições, e o efetivo exercício dos direitos sociais, o gap entre o direito e fatos sociais, a anomia e o estado de exceção. ” Em outras palavras, “ [...] corre-se o risco de uma democracia sem cidadãos. " (MISAILIDIS \& RÜDIGER, 2016, p. 32)

\section{CONCLUSÕES PARA UM DIREITO A SER (RE)INVENTADO}

Se há uma contribuição que a psicanálise pode dar para o debate sobre o direito no presente e no futuro, ela consiste na descoberta, por Sigmund Freud ([1915-1917] 2004, p. 273), do próprio inconsciente. "O Eu não é dono em sua própria casa." Consequentemente, a racionalidade humana e o exercício da vontade livre, tidos como bases do direito, são pressupostos filosóficos e jurídicos não mais sustentáveis e cambiáveis. Há desafios colocados ao direito pela sociedade contemporânea globalizada. Sua função 
primordial, hoje, é a de regular o convívio pacífico global sem recorrer ao moralismo ("ter que cumprir o dever em prol do convívio"), uma vez que não se age por dever moral, mas por motivos éticos, por atitudes que se toma para realizar uma convivência mais solidária e, com isso, dar vazão ao desejo que sempre se dirige ao outro ser humano.

Consequentemente, caberia ao direito possibilitar ao desejo humano desenvolver seu lado criativo, valorizando atitudes que os cidadãos conectados em rede, singularmente ou coletivamente, possam tomar para que seja possível uma convivência em comunidade local, regional ou global. O direito é capaz de acompanhar e possibilitar a reformatação das instituições. Podemos citar alguns exemplos. O direito do século XX já abriu e pode ampliar as possibilidades de participação - não somente formal, mas ativa dos filhos nas decisões da família, dos trabalhadores nas decisões das empresas, dos cidadãos nas decisões da comunidade. Pode incluir uma vasta gama de processos de consultas aos cidadãos, quando se trata de solucionar problemas de toda ordem e traçar os destinos de municípios, regiões e Estados. Cabe ao direito garantir a participação de representantes da coletividade na governança global, quando se trata da gestão dos desafios globais, tais como as mudanças do clima, o uso das novas tecnologias geradas pelas biociências e pela informática, ou, ainda, a garantia efetiva dos direitos fundamentais dos que migram, porque procuram refúgio ou simplesmente uma vida melhor.

Numa perspectiva lacaniana, o direito é uma das possíveis construções simbólicas em torno do Real, isto é, do incalculável, do inusitado, surpreendente e contingente. No entanto, o Real sempre escapa do alcance do direito. Isso traz desafios e chances para o direito. Se o direito for capaz de sair da lógica do "toma lá dá cá", construída ao longo do desenvolvimento da sociedade moderna, deixar para trás de si a lógica da "conta que fecha", do "justo balanço entre os direitos e obrigações", ele terá a chance de servir como 
Lei, Ética e Alienação do Desejo: Interpretação Psicanalítica...

instrumento de uma transformação criativa da sociedade, na qual os laços afetivos tomarão o lugar central.

Data de Submissão: 16/11/2018

Data de Aprovação: 22/01/2019

Processo de Avaliação: double blind peer review

Editor Geral: Jailton Macena de Araújo

Editor de Área: Jailton Macena de Araújo

\section{REFERÊNCIAS}

AGAmben, G. Estado de exceção. Tradução: Iraci D. Poleti. São Paulo: Boitempo, 2004.

BAUMAN, Z. Amor líquido: sobre a fragilidade dos laços humanos. Tradução: Carlos Alberto Medeiros. Rio de Janeiro: Zahar, 2004.

BENJAMIN, W. Sobre o conceito da história. In: . O anjo da história. Tradução: João Barreto. Belo Horizonte: Autêntica, [1940] 2012. p. 7-20.

BITTAR, E. C. B.; ALMEIDA, G. A. Curso de filosofia do direito. 8. ed. São Paulo: Atlas, 2010.

BOBBIO, N. Teoria do ordenamento jurídico. Tradução: Maria Celeste Cordeiro Leite dos Santos. 10. ed. Brasília: UnB, 1997.

BREUER, J.; FREUD, S. Studien über Hysterie. 6. Aufl. Frankfurt a.M.: Fischer, [1895] 2007. 
DE MASI, D. Alfabeto da sociedade desorientada: para entender o nosso tempo. Tradução: Silvana Cobucci e Federico Carotti. São Paulo: Objetiva, 2017.

FORBES, J. Inconsciente e responsabilidade: psicanálise do século XXI. Barueri: Manole, 2012.

FREUD, S. Jenseits des Lustprinzips. In: Das Ich und das

Es: metapsychologische Schriften. 12. Aufl. Frankfurt a.M.: Fischer, [1920] 2007. p. 191-249

FREUD, S. Die Traumdeutung. 13. Aufl. Frankfurt a.M.: Fischer, [1900] 2007.

FREUD, S. Tiebe und Triebsschicksale. In: . Das Ich und das Es: metapsychologische Schriften. 12. Aufl. Frankfurt a.M.: Fischer, [1920] 2007. p. 79-101

FREUD, S. Das Unbehagen in der Kultur. 9. Aufl. Frankfurt a.M.: Fischer, [1930] 2004.

FREUD. S. Vorlesungen zur Einführung in die Psychoanalyse. 13. Aufl. Frankfurt a.M.: Fischer, [1915-1917] 2004.

HARVEY, D. Condição pós-moderna: uma pesquisa sobre as origens da mudança cultural. Tradução: Adail Ubirajara Sobral e Maria Stela Gonçalves. 7. ed. São Paulo: Loyola, 1998.

LACAN, J. O estádio do espelho como formador da função do eu tal como nos é revelada na experiência psicanalítica. In:

Escritos. Tradução: Vera Ribeiro. Rio de Janeiro: Zahar, [1949]1998, p.96-103

LACAN, J. A direção do tratamento e os princípios de seu poder. In: Escritos. Tradução: Vera Ribeiro. Rio de Janeiro: Zahar, [1958] 1998. p. 591-652

LACAN, J. O seminário, livro 7: a ética da psicanálise, 1959-1960. Versão: Antônio Quinet. Rio de Janeiro: Zahar, 2008.

LACAN, J. O seminário, livro 10: a angústia. Tradução: Vera Ribeiro. Versão: Angelina Harari. Rio de Janeiro: Zahar, [1962-1963] 2005.

LACAN, J. O seminário, livro 11: os quatro conceitos fundamentais da psicanálise. Tradução: M. D. Magno. Rio de Janeiro: Zahar, [1964] 2008.

LACAN, J. Le séminaire, livre 17: l'envers de la psychanalyse. Paris: Seuil, [1969-1970] 1991. 
Lei, Ética e Alienação do Desejo: Interpretação Psicanalítica...

LACAN, J. Le séminaire, livre 20: Encore. Paris: Seuil, [19721973]1975.

LYOTARD, J.-F. A condição pós-moderna. Tradução: Ricardo Correa Barbosa. 5. ed. Rio de Janeiro: José Olympio, 1998.

MIAILLE, M. Introdução crítica ao direito. Tradução: Ana Prata. 3. ed. Lisboa: Estampa, 2005.

MISAILIDIS, M.G.L. \& RÜDIGER, D.S. Das noites em vigília à ocupação das escolas: Estado de exceção, subjetividade e direitos sociais na pós-modernidade. CONPEDI LAW REVIEW, Uruguai, v. 2, n. 4, p. 18-35, jul. -dez., 2016.

MARX, K.; ENGELS, F. A ideologia alemã. Tradução: Conceição Jardim e Eduardo Lúcio Nogueira. Lisboa/São Paulo: Presença/Martins Fontes, [1845-1846] 1980. v.1.

MARX, K. ; ENGELS, F. Manifesto comunista. Tradução: Maria Arsênio da Silva. São Paulo: CHED, [1848] 1980.

RÜDIGER, D.S. $O$ contrato coletivo no direito privado: contribuições do direito do trabalho para teoria geral do contrato. São Paulo: LTr, 1999.

RÜDIGER, D.S. Globalização e melancolia: a depressão como doença ocupacional. Cadernos de Direito, Piracicaba, v. 14, n. 27, p. 139-150, jul.-dez. 2014.

RÜDIGER, D.S. Assédio moral ou sadomasoquismo no trabalho: contribuições psicanalíticas para o debate de um problema jurídico trabalhista. Direito e Desenvolvimento, João Pessoa, v. 7, n.2, p. 4356, 2016.

SCHUMPETER, Joseph A. Capitalism, socialism and democracy. London: Routledge, [1943] 2003. Disponível em: $<$ http://digamo.free.fr/capisoc.pdf $>$. Acesso em: 16 novembro 2018.

W/MacCANN. Baton: Musical Não. YouTube, 8 de junho de 2014. Disponível em: $\quad<$ https://www.youtube.com/watch?v=-KJngT64kQ $>$. Acesso em: 16 novembro 2018. 


\title{
Law, Ethic and Alienation of Desire: Psychoanalytic and Legal Interpretation of Social Ties in Contemporary Capitalism
}

\author{
Dorothee Susanne Rudiger
}

\begin{abstract}
The article assembles reflections of law and psychoanalysis upon desire and contemporaneous social ties. Strange to modern law, desire is approached as an effect of law, which enables civilized coexistence. In a dialectic methodological perspective, the article argues the discovery of the unconscious within the historical context of and the movement of the "creative destruction" of capitalism. In addition, describes the consequences of the alienation of desire in various fields of legal knowledge. From the ethical perspective of psychoanalysis, which diverges from the moral bases of modern law, it researches new possibilities for the creation and maintenance of love and social ties through legal guarantee of participation in local, regional and global spaces in the social and political sphere. Proposes from the psychoanalytical point of view discussion in law aiming at overcoming the modern perspective of the fair balance between rights and obligations. It concludes, that law, in this way, will have the chance to serve as an instrument of a creative transformation of society, in which the affective ties will take a center stage.
\end{abstract}

Keywords: Law and psychoanalysis. Law and social ties. Law and postmodernity. 